University of Nebraska - Lincoln

DigitalCommons@University of Nebraska - Lincoln

$11-1-2005$

\title{
Inhibitory processes in young children and individual variation in short-term memory
}

Kimberly A. Espy

University of Nebraska-Lincoln, kespy2@unl.edu

Rebecca Bull

University of Aberdeen, Scotland, r.bull@abdn.ac.uk

Follow this and additional works at: https://digitalcommons.unl.edu/dcnlfacpub

Part of the Neurosciences Commons

Espy, Kimberly A. and Bull, Rebecca, "Inhibitory processes in young children and individual variation in short-term memory" (2005). Developmental Cognitive Neuroscience Laboratory - Faculty and Staff Publications. 3.

https://digitalcommons.unl.edu/dcnlfacpub/3

This Article is brought to you for free and open access by the Developmental Cognitive Neuroscience Laboratory at DigitalCommons@University of Nebraska - Lincoln. It has been accepted for inclusion in Developmental Cognitive Neuroscience Laboratory - Faculty and Staff Publications by an authorized administrator of DigitalCommons@University of Nebraska - Lincoln. 
Published in Developmental Neuropsychology, 28:2 (2005), pp. 669-688.

Copyright $\odot 2005$ Lawrence Erlbaum Associates, Inc. (Taylor \& Francis).

Used by permission.

\title{
Inhibitory Processes in Young Children and Individual Variation in Short-Term Memory
}

\author{
Kimberly Andrews Espy \\ Office of Research \& Department of Psychology \\ University of Nebraska-Lincoln \\ Rebecca Bull \\ School of Psychology \\ University of Aberdeen, Scotland
}

\begin{abstract}
A precise definition of executive control remains elusive, related in part to the variations among executive tasks in the nature of the task demands, which complicate the identification of test-specific versus construct-specific performance. In this study, tasks were chosen that varied in the nature of the stimulus (verbal, nonverbal), response (naming, somatic motor), conflict type (proactive interference, distraction), and inhibitory process (attention control, response suppression) required. Then performance differences were examined in 184 young children (age range $=3$ years 6 months to 6 years 1 month), comparing those with high (5 or more digits) and low ( 3 or fewer digits) spans to determine the dependence on short-term memory. Results indicated that there was communality in inhibitory task demands across instruments, although the specific pattern of task intercorrelations varied in children with high and low spans. Furthermore, only performance on attention control tasks - that is, that require cognitive engagement/disengagement among an internally represented rule or response set that was previously active versus those currently active-differed between children of high and low spans. In contrast, there were differences neither between children with high and low spans on response suppression tasks nor on tasks when considered by type of stimulus, response, or conflict. Individual differences in wellregulated thought may rest in variations in the ability to maintain information in an active, quickly retrievable state that subserve controlling attention in a goalrelevant fashion.
\end{abstract}


$\mathrm{E}$ xecutive control plays a critical role in normative cognitive processes, such as memory, attention, and consciousness/theory of mind (e.g., Baddeley \& Hitch, 1994; Desimone \& Duncan, 1995; Posner \& Petersen, 1990; Hughes, 1998b; Perner, Lang, \& Kloo, 2002) and is related to important academic and behavioral/social outcomes (e.g., Bull, Johnston, \& Roy, 1999; Bull \& Scerif, 2001; Espy et al., 2004; Gathercole \& Pickering, 2000; Hughes, White, Sharpen, \& Dunn, 2000; Isquith, Gioia, \& Espy, 2004; Ready, Stierman, \& Paulsen, 2001). Not surprisingly, executive control is fundamental to etiology of, or at least a significant contributor to, diverse clinical disorders (e.g., Anderson, Anderson, Grimwood, \& Nolan, 2004; Espy, Kaufmann, \& Glisky, 1999; Espy et al., 2002; Ewing-Cobbs, Prasad, Landry, Kramer, \& DeLeon, 2004; Pennington \& Ozonoff, 1996). Although there are many models of executive control, largely derived from neuropsychological performance of adults, one underutilized method to understand the nature of executive control is to examine such skills early in ontogeny, when abilities are developing rapidly. There is substantial evidence across diverse tasks that the preschool period is a phase of rapid acquisition of executive competencies that are supported by substantial maturation in prefrontal structures and functional systems (e.g., Huttenlocher \& Dabholkar, 1997; Kinney, Brody, Kloman, \& Gilles, 1988; Thatcher, 1997). In fact, Diamond and Kirkham (2005) recently noted that adults show the same stimulus-response biased performance on a simple card sorting task that most 4-year-old children "pass," suggesting substantial continuity of executive control from early development to maturity.

Although the precise nature of executive control in adults, or children, is far from resolved, what differs among the various accounts is whether executive control is (a) viewed as a unitary process or composed of "fractionated," interdependent subprocesses; (b) the relative weights or uniqueness that these executive constructs are ascribed; (c) differentially localized within the brain, and/or (d) the manner or pattern of development during childhood. Executive control has been studied in typically developing preschool children with several paradigms, including rule-governed, attribute-based sorting tasks (Espy, Kaufmann, \& Glisky, 1999; Hughes, 1998a) such as the Dimensional Change Card Sort task (DCCS; see Zelazo, Frye, \& Rapus, 1996); tasks with manual selection or verbal naming of stimuli that conflict or interfere on the basis of natural associations (e.g., Carlson \& Moses, 2001; Diamond, Briand, Fossella, \& Gehlbach, 2004; Diamond, Kirkham, \& Amso, 2002; Gerstadt, Hong, \& Diamond, 1994; Prevor \& Diamond, 2005; Wright, Waterman, Prescott, \& Murdoch-Eaton, 2003); and manual search tasks with working memory maintenance demands (e.g., Espy, Kaufmann, Glisky, \& McDiarmid, 2001; Diamond, Prevor, Callender, \& Druin, 1997; Hughes, 1998a) and/or with inhibiting pre potent or prohibited somatic motor responses (e.g., Carlson \& Moses, 2001; Diamond 
\& Taylor, 1996; Espy, Kaufmann, McDiarmid, \& Glisky, 1999; Kochanska, Murray, Jacques, Koenig, \& Vandegeest, 1996; Korkman, Kirk, \& Kemp, 1998; Reed, Pien, \& Rothbart, 1984).

To provide a unified account across the diverse tasks used to measure executive control, Diamond recently argued that "attentional inertia" underlies the classic dysexecutive behavior that young children display, such as, persisting to search at a previously rewarded location that no longer contains the reward, sorting a new card to the previously active category despite explicit recall of the current sorting "rule," and impulsively performing a prohibited act (Kirkham, Cruess, \& Diamond, 2003). Similar to the concept of task-set inertia discussed in the adult cognitive literature (Allport, Styles, \& Hsieh, 1994; Allport \& Wylie, 2000), Diamond and colleagues argued that the young child's attention gets pulled away from the response set at hand by conflicting stimulus properties, thereby disrupting performance and leading to the classic dissociation between knowledge and action. In this view, inhibition resolves the conflict among stimulus properties, response mappings, and current context demands, essentially permitting the child to activate one rule or response in one context, then cognitively disengage when the context changes and, in turn, engage another newly salient but competing response or set. Strong support for this type of conceptualization is provided in the adult cognitive literature, where evidence of backward inhibition (e.g., Mayr \& Keele, 2000) and negative priming (e.g., Tipper \& Cranston, 1985) are some likely mechanisms that might underlie such "inertia."

Unfortunately, in the developmental and pediatric literatures in particular, the term inhibition has been used to describe both the suppression of a prepotent (and typically somatic, motor response) and the control of attention - that is, cognitive engagement/disengagement among internally represented rules or response sets that are previously active versus those currently active (Harnishfeger, 1995; Nigg, 2000). In suppression tasks, the child must suppress somatic motor responses - for example, remaining still while the examiner tries to distract the child. In attention control tasks, the child must inhibit an internally represented rule or response set that had been previously active and now must be disengaged and controlled due to proactive interference, which interferes with the child's ability to engage and implement a new response or rule. Friedman and Miyake (2004) found evidence for such a distinction using structural equation modeling, where normative adult task performance was characterized by (a) inhibiting a prepotent response or resisting interference from irrelevant distraction versus (b) controlling attention to resist proactive interference from a previously active rule or response set. Although the attentional inertia conceptualization applies to the attention control view in a straightforward fashion, it is less clear how such attentional inertia might function in the suppression of a somatic motor response or whether, in fact, these two inhibitory processes are distinguishable (Bishop, Aamodt-Leaper, Creswell, 
McGurk, \& Skuse, 2001; Nigg, 2000; Wilson \& Kipp, 1998), particularly in young children. Of note are the factor analytic findings of Carlson and Moses (2001), who identified two factors that best described the performance of 107 three- and four-year-olds on 10 inhibitory tasks, which they labeled conflict and delay. Inspection of the pattern matrix revealed that the conflict factor is composed of tasks that demand control of attention as described here, and the delay tasks were largely those that required response suppression (or moderation), consistent with this inhibitory framework.

Further complicating this issue is the fact that the nature of the conflict varies among executive tasks. In motor response suppression tasks, the conflict typically is derived through a prohibited action or resistance to obtaining reward. In other executive tasks like "Day-Night" (Gerstadt et al., 1994), Luria's tapping task (Diamond \& Taylor, 1996), Dots (Diamond et al., 2004), and Color-Object Stroop (Prevor \& Diamond, 2005), the conflict between the response and the stimulus conditions are derived from the child's experience in the natural environment. That is, there is a "natural" stimulus-response mapping, for example, between the picture of a sun in a sky and the word day that is entrenched from the child's participation in his or her everyday sensory, motor, and linguistic environment. Finally, in the DCCS, there is conflict between the stimuli properties and the required response, but the conflict between the two dimensions is arbitrary (e.g., color is not inherently related to shape). Inhibiting or controlling responding in light of conflict appears to be critical in engaging prefrontal systems (e.g., Casey et al., 2000; Durston et al., 2002), as some postulate that this conflict between stimulus-response mappings and new reward contingencies is the fundamental nature of executive control (e.g., Miller, 2000; O'Reilly, Noelle, Braver, \& Cohen, 2002). In fact, even in very young children, conflict is critical to executive task performance, as 3-year-olds can sort the conflicting cards successfully when the second dimension is not present (Brooks, Hanauer, Padowska, \& Rosman, 2003) or is irrelevant to sorting (Perner \& Lang, 2002; Rennie, Bull, \& Diamond, 2004), or when the response is not canonically related (Diamond et al., 2002). It remains unclear whether all types of conflict invoke executive control, or perhaps whether the nature of conflict required differs with age or cognitive proficiency.

Finally, most of the executive tasks developed to date are nonverbal in stimulus content and/or response. Dempster (1993) proposed that interference control in the motoric, linguistic, and perceptual domains may not be a unitary process. Indeed, Prevor and Diamond (2005) recently developed the Color-Object Stroop task that utilized a naming response of verbal material. They noted a significantly larger effect of conflict when the response was a naming response in comparison to a manual selection response. However, this distinction likely is complicated, as verbal material introduces another level of complexity with respect to semantic relations and phonological similarity, for example, which may or may not account for the conflict effects noted on a given task (Bull \& Brown, 2004). The advantages of more verbally 
laden executive tasks is the potentially stronger relations to outcomes of interest that both more heavily demand verbal skills and utilize a verbal presentation format, such as emergent reading and mathematics achievement (e.g., Bull \& Scerif, 2001; Espy et al., 2004; Gathercole \& Pickering, 2000).

The purpose here was to better characterize the nature of executive control by examining inhibition task demands - the nature of the stimulus, response, conflict, and inhibitory process - as a function of individual differences in working memory. For example, Diamond (1988) postulated that inhibition and working memory are inextricably linked, where if an individual is not able to maintain information over time and/or inhibit prepotent responses, he or she will continue to inflexibly choose the incorrect response. Similarly, Roberts and Pennington (1996) theorized that inhibition and working memory are in a competitive balance, so that as the demands for one increase, the other necessarily decreases. Both of these models are difficult to test empirically, particularly in young children. Engle and colleagues used an individual differences approach in adults to investigate this issue by comparing performance in adults with high versus low working-memory spans on several attention/executive tasks, including Proactive Interference (Kane \& Engle, 2000), Stroop (Kane \& Engle, 2003), Prosaccade (Kane, Bleckley, Conway, \& Engle, 2001), and Visual Attention (Bleckley, Durso, Crutchfield, Engle, \& Khanna, 2003). Results consistently revealed that task performance was reduced only in high-span individuals (and not those with low spans) when the proactive intereference, distraction, or conflict load was increased relative to baseline task demands. Engle (2002) cogently concluded that the fundamental, domain-free executive ability rests in individual differences in the ability to "control attention to maintain information in an active, quickly retrievable state ... . It is about using attention to maintain or suppress information" (p. 20). Therefore, a similar individual difference approach might be useful in young children to better understand the specific task conditions under which executive control is engaged.

Using this approach, individual differences in young children's memory span were hypothesized to reflect variation in the fundamental process of attention control. Short-term memory span likely is utilized in attention control to maintain the currently active stimulus-response mapping among previously active mappings that now provide proactive interference and to retrieve the correct response to achieve flexible, well-regulated thought or behavior. Therefore, children with high spans should perform better than those with low spans on inhibitory tasks that demand attention control relative to those that instead require response suppression. For similar reasons, individual variation in memory span instead might subserve demands to resist interference from proactive information, more broadly, as proposed by Wilson and Kipp (1998). In this case, task performance will differ in children with high versus low spans across tasks where the conflict is derived through proactive interference rather than through distraction. Given the domain-specific views articulated by Dempster (1993) and the shared ver- 
bal nature of span and verbal executive tasks, task performance might differ as a function of stimulus type demands. However, in Baddeley's (1996) model of working memory, both verbal and nonverbal information is maintained through separate work spaces (the phonological loop and visual spatial sketch pad, respectively) and available for central executive processing; therefore, verbal and nonverbal stimulus-type task performance might not differ in children with high versus low spans. Similarly, response type can be considered an "output" mechanism, and therefore performance among tasks that differed in the type of response demands were not hypothesized to differ in children with high versus low spans.

\section{Method}

\section{Participants}

The sample was composed of 184 typically developing children who ranged in age from 3 years 6 months to 6 years 1 month $\left(M_{\text {age }}=4.84\right.$ years, $S D_{\text {age }}=0.50$ years). There were 103 girls $(56 \%)$ and 81 boys. Similar to the demographics of the local area, $85 \%(n=156)$ of the sample were Caucasian, 19 children were African American, 7 were Asian, and 2 were of mixed race. Mean maternal education level of the sample was 14.2 years $(S D=2.3)$. By parental report, none of these children were diagnosed with any neurological, psychiatric, or developmental disorders.

Preschool children were divided into three groups according to their maximal string length recalled on a forward digit span subtest that was administered during the test session. There were 72 children with a digit span of 3 or fewer, 70 children with a span of 4 , and 42 with a span of 5 or more. The sex distribution across digit span groups was comparable, $\chi^{2}(2$, $N=184)=1.83, p>.39$, however age was not. Not surprisingly, there were more younger children with a maximal digit span of 3 or fewer and more older children with a maximal span of 5 or more, $F(2,181)=9.19, p<.01$. Therefore, the effect of age was controlled in all analyses.

\section{Materials}

To parse children by span length, a standardized forward digit span task was administered; then after an initial practice session, a standard sequence of digits was presented orally, starting from a span length of two. Each child was instructed to recall the digit strings in the order of presentation, with a maximum of two trials at each string length, and the maximum digit span length was recorded. The relation between inhibitory processing and shortterm memory was investigated by focusing on a verbal executive task, the Shape School (Espy, 1997; Espy, Bull, \& Martin, 2005). Using a storybook format that is familiar and appealing to young children, conflict between the arbitrary relation between the stimulus properties and the response is progressively built up through the story theme. Then, other comparison tasks 
were chosen that varied in stimulus content (verbal vs. nonverbal), response type (somatic motor vs. naming), inhibitory demands (attention control vs. response suppression), and type of conflict (proactive interference vs. distraction) to form a matrix of comparative task demands, as depicted in Table 1. Consistent with the approach used by Friedman and Miyake (2004), the comparison tasks were selected purposefully among those that are commercially available or that have an extensive literature base in order to increase generalizability and applicability in the clinical context. Of course, the disadvantage of this approach is that the degree of task demand control is inherently reduced. Nonetheless, applicability to extant literature was central in task selection, particularly as an initial approach.

Shape School. The Shape School, developed by Espy (1997), is designed to assess different aspects of executive control in young children by using colorful, affectively engaging stimuli presented in an age-appropriate, storybook format. The story begins by setting up the premise, showing stimulus figures (colored squares and circles with cartoon faces, arms, and legs) playing on a playground and then going on to different school activities throughout the story. In each condition, the child must "call" / name the figure for it to proceed to the relevant school activity by the relevant rule. Briefly (see Espy, 1997; Espy et al., 2005, for a more thorough description), in the first control condition to establish the stimulus-response mapping, the child is introduced to one classroom of figures whose names are their color, where the child then had to call/name the color of each figure arrayed in three lines of five across the page. In Condition B, children were told that not all of the story figures had finished their work, where Happy $(n=9)$ and Sad/Frustrated $(n=6)$ expressions were added to the stimulus figures' faces to depict this contingency. These facial expressions served as cues to which stimuli the child was to name and which to sup-

Table 1. Task Demands by Inhibitory Measures

\begin{tabular}{|c|c|c|c|c|}
\hline Task & $\begin{array}{l}\text { Stimulus } \\
\text { Type }\end{array}$ & $\begin{array}{c}\text { Response } \\
\text { Type }\end{array}$ & $\begin{array}{c}\text { Inhibitory } \\
\text { Process }\end{array}$ & $\begin{array}{l}\text { Conflict } \\
\text { Type }\end{array}$ \\
\hline Shape School-C & Verbal & Naming & $\begin{array}{c}\text { Attention } \\
\text { control }\end{array}$ & $\begin{array}{l}\text { Proactive } \\
\text { interference }\end{array}$ \\
\hline Shape School-B & Verbal & Naming & $\begin{array}{l}\text { Response } \\
\text { suppression }\end{array}$ & $\begin{array}{l}\text { Proactive } \\
\text { interference }\end{array}$ \\
\hline NEPSY Statue & Nonverbal & $\begin{array}{c}\text { Somatic } \\
\text { motor }\end{array}$ & $\begin{array}{l}\text { Response } \\
\text { suppression }\end{array}$ & Distraction \\
\hline Delayed Search & Nonverbal & $\begin{array}{c}\text { Somatic } \\
\text { motor }\end{array}$ & $\begin{array}{l}\text { Response } \\
\text { suppression }\end{array}$ & $\begin{array}{c}\text { Proactive } \\
\text { interference }\end{array}$ \\
\hline NEPSY Visual Attention & Verbal & $\begin{array}{l}\text { Somatic } \\
\text { motor }\end{array}$ & $\begin{array}{c}\text { Attention } \\
\text { control }\end{array}$ & Distraction \\
\hline
\end{tabular}


press naming. In Condition $C$, a classroom was added where the stimulus figures wore hats; for figures with hats $(n=8)$, the names were the stimulus figure shapes, and for hatless figures $(n=7)$, the names remained the color. For each condition, there was a brief practice page on which children had to demonstrate success to ensure adequate rule knowledge prior to application in the test conditions. The experimenter recorded the response time and number of stimuli correctly identified (according to the pertinent rule) in each condition from when the child began naming the first figure to when he or she finished naming the last figure in the array. For the purposes here, an efficiency score was calculated for each condition by dividing the number of stimuli correctly named by the latency to complete each condition. Analysis of task demands of these two conditions reveals that both Conditions $\mathrm{B}$ and $\mathrm{C}$ utilize identical verbal stimuli and naming responses. For both conditions, the first stimulus-response mapping (name color) provides proactive interference for the implementation of the second ( $\mathrm{B}=$ suppress color name; $\mathrm{C}=$ name shape), in light of a relatively constant working-memory load of maintaining two rules in mind where overt cues signal the correct stimulus-response mapping. The two conditions differ with respect to the type of inhibitory process demanded, with Condition $B$ requiring response suppression and Condition $C$, attention control, as shown in Table 1.

Statue. Statue is a NEPSY subtest (Korkman et al., 1998), where the child is asked to stand still in a set position as a "statue" pretending to hold a flag (i.e., with eyes closed, no body movements or vocalizations) over 75 sec. At set intervals to distract and induce the child to break the statue posture, the examiner coughs, knocks on the table, drops a pencil, or says "Ho Hum!" For each 5 -sec epoch, the child is awarded 2 points if no inappropriate responding is noted (i.e., keeps eyes shut without movement or vocalization), 1 point for one inappropriate response, and 0 points if the child fails to inhibit more than one response, with a maximum score of 30 . Like Shape School Condition B, this task demands suppression of response; however, it requires a somatic motor rather than naming response. Furthermore, conflict is provided through distraction, and the stimulus type is nonverbal.

Delayed Search task. In this venerable task adapted from the neuroscience literature (e.g., Diamond, 1988), the child watched while a reward was hidden under a cup at one of two locations. After a 10-sec delay, the child retrieved the reward. This procedure was repeated for 10 trials, and the percentage of correct retrievals was scored. Here, the stimulus type is nonverbal, and the response type was somatic motor in nature. To inhibit reaching to the previously rewarded location, the child had to suppress a somatic motor response. The conflict is provided by the proactive interference from the previously searched and/or rewarded location. 
Visual Attention. In this NEPSY subtest (Korkman et al., 1998), the child was instructed to select only the items that match the target stimuli on the page containing both targets and distractors. Only the random cat array was used, as it is common to both older and younger children. The number of targets (maximum 20 cats) correctly identified and completion time (maximum $180 \mathrm{sec}$ ) were scored. Like the two Shape School tasks, the stimulus type is verbal; however, a somatic motor response is required to be suppressed. Like Statue, the conflict is engendered through irrelevant distractors arrayed on the page. Given the role of attention control in visual search processes (e.g., Bleckley et al., 2003; Han \& Kim, 2004), this task was considered to be an attention control task, consistent with the task demands to search and select of relevant targets amidst consideration of irrelevant stimuli.

\section{Procedure}

Preschool children were administered the inhibitory tasks in a single 90- to 120-min session by a trained child clinical graduate student blind to the experimental hypotheses. Assessments were conducted individually in a quiet room, with the parent or guardian present in the back of the room, completing study forms, to minimize any separation issues in the youngest of children. To foster cooperation and interest, short breaks were used, and families received monetary and small trinket compensation for study participation.

\section{Results}

First, Pearson correlations were conducted to determine the interrelatedness of the different inhibitory tasks. In the overall sample (in the bottom left quadrant in the first panel in Table 2), all but one correlation was significant. The magnitudes of the correlations were moderate. There was a relatively small difference in the pattern of correlations when partial correlations were examined with age controlled (in the top right quadrant of the same panel). Cronbach's alpha for the five outcome measures was .63, lending further support to a general communality in task demands. Furthermore, separate intertask Pearson correlations were calculated for children with low and high spans. Informal examination of the pattern of the strength of correlations across the three digit span groups revealed that performance on Shape School Condition B and Statue were unrelated in children with different span lengths. The association between performance on Statue and Shape School Condition C differed in magnitude across digit span groups, such that there was a moderate relation in children with a digit span of 3 or fewer and correlation close to zero in children with a digit span of 5 or more. The pattern also was similar for the relation between Visual Attention and Statue performance, again where moderate relations 
Table 2. Intertask Correlations for the Overall Sample and by Digit Span Group

\begin{tabular}{lllllll}
\hline & \multicolumn{2}{c}{ SS } & & & \\
\cline { 2 - 3 } Task & $\mathrm{C}^{\mathrm{a}}$ & $\mathrm{B}^{\mathrm{a}}$ & & Statue $^{\mathrm{b}}$ & $\mathrm{DS}^{\mathrm{c}}$ & VA $^{\mathrm{d}}$ \\
\hline SS-C & - & $.47^{* * * *}$ & $.17^{*}$ & $.28^{* * *}$ & $.22^{* *}$ \\
SS-B & $.53^{* * * *}$ & - & .02 & .13 & $.23^{* *}$ \\
Statue & $.18^{*}$ & .05 & - & $.29^{* * *}$ & $.17^{*}$ \\
DS & $.30^{* * *}$ & $.16^{*}$ & $.30^{* * *}$ & - & $.16^{*}$ \\
VA & $.32^{* * * *}$ & $.34^{* * *}$ & $.18^{*}$ & $.18^{*}$ & - \\
SS-C & - & $.46^{* * *}$ & $.26^{*}$ & $.35^{* *}$ & .26 \\
SS-B & $.60^{* * * *}$ & - & .09 & .12 & $.29^{*}$ \\
Statue & .00 & .01 & - & $.40^{* *}$ & $.33^{*}$ \\
DS & .25 & .10 & $.37^{*}$ & - & .20 \\
VA & $.40^{*}$ & .25 & .00 & .14 & - \\
\hline
\end{tabular}

First panel are the first-order correlations for the entire sample (bottom left) and partial correlations with age controlled (top right); second panel are the correlations for children with a digit span of $=3$ (bottom left), and top right of the second panel are the correlations for children with a digit span of $=5$. SS $=$ Shape School; DS = Delayed Search; VA = NEPSY Visual Attention.

${ }^{\mathrm{a}} n=184 .{ }^{\mathrm{b}} n=159 .{ }^{\mathrm{c}} n=146 .{ }^{\mathrm{d}} n=143$.

${ }^{*} p<.05 ;{ }^{* *} p<.01 ;{ }^{* * *} p<.001 ;{ }^{* * *} p<.0001$.

were observed in children with spans of 3 or fewer, and no relation was evident in children with spans 5 or more. The opposite pattern was observed for the association between Visual Attention and Shape School Condition $\mathrm{C}$, where the magnitude of the association was higher in those with longer spans than in those children with span lengths of 3 or fewer digits.

The joint effect of short-term memory span capacity and task demand was examined using repeated measures multivariate analyses of variance (MANOVAs), comparing performance across the tasks collapsed by the four task demands (shown in Table 1) in children with high (maximal digit span length of 5 or more) and low (maximal span of 3 or fewer) digit recall spans, using Engle's individual difference approach. For example, the $z$ scores from Shape School Condition C and Visual Attention performance were averaged to index Attention Control task performance, as were the $z$ scores from Shape School Condition B, Statue, and Delayed Search to index Response Suppression. Then, these respective averaged $z$ scores were treated as a within-subjects condition and compared between children with high and low spans. Separate MANOVAs were conducted for each task demand, with the pertinent variables transformed into averaged $\mathrm{z}$ scores to reduce individual variable scale effects. When there was missing data on an individual task (9 children with one task only [2 Statue, 1 Delayed Search, 6 Visual Attention], 11 children with two tasks [9 Delayed Search 
and Visual Attention; 2 Statue and Visual Attention]; and 21 children with three tasks [Statue, Delayed Search, and Visual Attention]), the averaged $\mathrm{z}$ score was based on the remaining task data. There were no differences in age between children with and without missing data for any task, $p$ s > .23. Because there was an expected age difference between children of the varying span lengths (e.g., Cowan, 1995, 1999), all analyses were conducted controlling for age. Overall sample task performance, and that of the differing digit span lengths, is shown in Table 3.

Consistent with prediction, performance collapsed across inhibitory process demands (Attention Control vs. Response Suppression) differed in children with high and low span lengths, $F(1,111)=5.58, p<.02$. The average $\mathrm{z}$ score for performance on tasks that required attentional control (controlling for age) for children with a low span length was -.21, whereas for children with a high span length, average $\mathrm{z}$ score on attentional control tasks was .25. Follow-up analyses revealed that performance differed on attentional control tasks in children of high and low spans, $F(1,111)=8.53, p$ $<.01$. Univariate analyses on each task revealed that task performance between children of high and low spans differed to a greater extent on Shape School Condition C, $F(1,89)=7.80, \mathrm{p}<.001$, than on Visual Attention, $F(1$, $89)=0.84, p>$.36. As hypothesized, response suppression task performance did not differ between children of high and low spans, $F(1,111)=0.25, p$ $>.61$, where the average $z$ scores in the digit span groups were comparable $\left(M_{\leq 3 \text { digit span }} z=-0.07 ; M_{\leq 5 \text { digit span }} z=0.01\right)$.

Of interest, performance on tasks collapsed by conflict demand (i.e., comparing those that utilized proactive interference vs. those with distraction) did not differ in children with high and low spans, $F(1,111)=0.71$, $p>.40$. Because the overall Task $\times$ Digit Span Group effect was not significant, further group differences were not explored. Consistent with prediction, children of high and low spans performed equivalently on tasks

Table 3. Overall Sample Task Performance and Performance in Child of Varying Digit Spans

\begin{tabular}{|c|c|c|c|c|c|c|c|c|}
\hline \multirow[b]{2}{*}{ Task } & \multicolumn{2}{|c|}{ Overall Sample ${ }^{a}$} & \multicolumn{2}{|c|}{ Digit Span $3^{b}$} & \multicolumn{2}{|c|}{ Digit Span $4^{\mathrm{c}}$} & \multicolumn{2}{|c|}{ Digit Span $5^{\mathrm{d}}$} \\
\hline & $M$ & $S D$ & $M$ & $S D$ & $M$ & $S D$ & $M$ & $S D$ \\
\hline \multicolumn{9}{|l|}{ Shape School } \\
\hline Condition C & 0.19 & 0.17 & 0.14 & 0.13 & 0.20 & 0.20 & 0.26 & 0.16 \\
\hline Condition B & 0.63 & 0.31 & 0.57 & 0.28 & 0.65 & 0.33 & 0.73 & 0.33 \\
\hline Statue & 22.59 & 7.19 & 21.64 & 6.95 & 23.53 & 7.10 & 22.53 & 7.65 \\
\hline Delayed Search & 0.87 & 0.12 & 0.86 & 0.13 & 0.88 & 0.11 & 0.86 & 0.12 \\
\hline Visual Attention & 0.23 & 0.09 & 0.21 & 0.08 & 0.23 & 0.09 & 0.25 & 0.09 \\
\hline
\end{tabular}

Shape School Condition efficiency $=$ naming accuracy $/$ completion time; Statue $=$ subtest total raw score; Delayed Search $=\%$ of correct searches/total trials; Visual Attention efficiency $=$ stamping accuracy $/$ completion time. 
that varied as a function of stimulus type (verbal vs. nonverbal), $F(1,111)=$ $3.04, p>.08$. Contrary to prediction, performance on tasks that differed in response type (naming vs. somatic motor) differed marginally among children of high and low spans, $F(1,111)=3.70, p>.05$. The digit span effect was restricted to the naming response type only, $F(1,111)=6.93, p<.01$, in contrast to that for somatic motor response, $F(1,111)=0.28, p>.60$. Univariate analyses on each task revealed that task performance between children of high and low spans differed to a greater extent on Shape School Condition $C, F(1,111)=11.83, p<.001$, than on Shape School Condition B, $F(1$, $111)=1.60, p>.20$

\section{Discussion}

These findings suggest that these inhibitory processes, namely attention control and response suppression, indeed differed in young children, at least in their dependence on short-term memory processes. In contrast, there were no differences between children of high and low spans in performance on inhibitory tasks parsed on the basis of type of conflict, interference from previous responses (proactive interference), or interference from irrelevant stimuli (distraction).

First, the inhibitory tasks generally were intercorrelated, with adequate coherence in content among the inhibitory tasks. Therefore, there was meaningful and coherent variation in performance across inhibitory tasks, at least in this young age range, even when the influence of age was removed. This communality differs from what is typically found in adults, where performance even on executive tasks that are quite similar in format often are unrelated (e.g., Shilling, Chetwynd, \& Rabbitt, 2002). Immature abilities often are considered less differentiated, which likely resulted in greater coherence in inhibitory test performance than is observed in older children and adults. This communality, however, provides support that the tasks selected measure a common construct and further substantiate the examination of performance discrepancies among tasks with differing task demands.

In contrast to children with higher spans, children with lower memory spans were less able to inhibit an internally represented rule or response set that had been previously active or were less proficient in disengaging and controlling attention, which then interfered with the child's ability to engage and implement a newly relevant response or rule. These inhibitory task performance discrepancies among children of high and low spans are consistent with those observed by Engle and colleagues (Bleckley et al., 2003; Kane \& Engle, 2000, 2002, 2003) in adults, using a similar design but a different span task by which to parse groups. These findings support Diamond's (Kirkham et al., 2003) attentional inertia conceptualization, where the young child's attention is pulled away from the response set at hand by stimulus properties that are discrepant from current task demands, thereby disrupt- 
ing performance. In this view, better short-term memory facilitates the child in activating of one rule or response in one context, then cognitively disengaging when the context changes and, in turn, engaging another newly salient but competing response or set. More broadly, the key to well-regulated thought may be individual differences in the ability to control attention to maintain information in an active, quickly retrievable state (Engle, 2002). Short-term memory processes, however, are composed of encoding, storage, and retrieval components. Although performance differences in children of high and low spans were more evident on the Shape School Condition C, span-related differences were capture both by naming accuracy and speed. In this vein, one might speculate that both short-term memory storage and retrieval contributed to task performance, evidenced by naming accuracy and speed measures, respectively. Such a conceptualization also is consistent with Zelazo's view (Zelazo, Müller, Frye, \& Marcovitch, 2003), where short-term memory processes might facilitate the coding of stimulusresponse mappings or "rules" that, in turn, facilitate more efficient task performance in a top-down manner. However, with the present design and the crude dependent measure of digit span length, it is not possible to truly determine the relative roles of short-term storage or retrieval mechanisms in this observed effect, or whether digit span represents a proxy for the influences of other variables not considered here (e.g., general verbal ability).

Of note, performance differences between children of differing spans were most evident on Shape School Condition C relative to Visual Attention. Where both tasks require attentional control in the continual selective processing of differentially relevant stimuli features, only Condition C involves active selection of the relevant mapping of a differential response to the relevant stimulus feature. In Visual Attention, there is no selection among alternative responses, in that the child always stamps the relevant stimulus. In this age range, the greater, concurrent demands to control attention in the selection of both the relevant stimulus and relevant response likely is facilitated in children with better short-term memory. Carlson and Moses (2001) found that a matching figures task loaded on the Delay factor, which was not related to working memory (Carlson, Moses, \& Breton, 2002), possibly because it requires suppressing an impulsive response to carefully inspect each item where memory demands are relatively low. Greater investigation of the relative attentional control demands through systematic variation at both the stimulus and response levels would be useful to address this issue.

In contrast, on inhibitory tasks considered to require response suppression, namely Shape School Condition B, Statue, and Delayed Search, performance did not differ in children with differing digit span lengths. In the preschool age range, rather, these findings broadly support Nigg's (2000) distinction, if "behavioral" inhibition is construed as response suppression and "cognitive" inhibition as attention control, at least in the differential dependence on short-term memory processes. Wilson and Kipp (1998) argued that attentional control is utilized to operate on the contents 
of working memory, providing the basis for resistance to interference and engendering fluid, regulated task performance. In the case of response suppression, short-term memory processes do not appear to play a role in individual differences in task proficiencies, suggesting that the behavioral inhibition occurs at a more primary, nonmnemonic level. Such findings may not be surprising given the often noted discrepancies on tasks of motor action/impulsivity and cognitive attention in children diagnosed with attention deficit hyperactivity disorder (e.g., Bedard et al., 2003; Nigg, 2001).

These findings also parallel the noted conflict versus delay distinction of Carlson and Moses (2001), where conflict tasks in that study are similar in scope to attention control tasks labeled here, and delay to the response suppression tasks. Of note is the consistency in findings, despite the younger age range in the Carlson and Moses study. Some have argued that response suppression tasks represent a form of inhibition that matures earlier in development and that such abilities emerge earlier in life (e.g., Anderson, 1998; Welsh, Pennington, \& Groisser, 1991), in 2-and 3-year-olds for example, are earlier manifestations of later attentional control (e.g., Gerardi-Caulton, 2000). The pattern of correlations observed here sheds some light on this issue. Note the weak relation among performance on Statue and Shape School Condition $\mathrm{B}$ across children with differing digit span lengths studied here, suggesting that these types of suppression tasks may not be isomorphic. However, the pattern of relation to Shape School Condition B and the other response suppression task, Delayed Search, across digit span lengths differed, suggesting that response suppression per se may not develop early. Rather, proficiency in resolving conflict provided through prohibited action is an earlier, developmentally bound manifestation of attentional control. Performance on similar prohibited action tasks (e.g., Espy et al., 2001; Kochanska et al., 1996; Reed et al., 1984) provides such evidence for this view, both in studies using cross-sectional and longitudinal designs, as well as the lack of systematic differences in difficulty level across conflict and delay tasks across age (Carlson, this issue). However, caution is required when trying to discern patterns of ability maturation from observed test performance. Psychometrically, observed test performance is constrained both by true score variance, in this case the inhibitory process of interest, and error variance that here includes test specific variance. One of the particular challenges with characterizing the maturation of inhibitory processes is that inhibition necessarily includes some other abilities (the target of the inhibition), thereby necessarily increasing nonconstruct specific variance (Freidman \& Miyake, 2004). Clearly, to address this question adequately, designs that include multiple measures of the relevant inhibitory construct are necessary to reliably characterize latent ability growth.

Based on examination of the demand characteristics of the differing inhibitory tasks and child performance on these tasks, it does not appear that the distinction between conflict type (i.e., between proactive interference and resistance to distraction) is a relevant one in this age range. In one 
view, short-term memory processes might be important in resistance to proactive interference, more broadly. However, based on the results shown here, the influence of short-term memory processes seems to be more limited to attention control, more specifically. These findings do not support Nigg's (2000) or Wilson and Kipp's (1998) distinction of interference control and are contrary to findings in adults by Friedman and Miyake (2004), who used structural equation modeling to characterize the distinct conflict demands. Statistical modeling likely is a superior procedure due to the latent nature of conflict demands, and the findings reported here might reflect the different statistical procedures and design. Because our study was conducted in preschool children, the discrepancy in findings simply may represent relative immaturity in preschool children relative to adults, in the cognitive system that recognizes variations in conflict demands. Alternatively, both types of conflict might elicit executive processes that are indistinguishable at this young age, unlike in adults. Further cross-sectional studies in school-age children, and longitudinal investigations that track the transition from the preschool to elementary school age ranges will be important to better address this issue.

Individual variations in digit span length also were not related to task performance that differed in the type of stimulus, in keeping with the domain-general view of inhibitory processes (e.g., Engle, 2002). Contrary to prediction, performance on tasks parsed by response type differed among children of varying spans, although the effect was limited to naming, a demand that is common to digit span also. The goal here was to include tasks with a sufficient range of demands, which varied in the type of stimulus, response, and conflict. The focus on using clinically available comparison tasks, similar to Friedman and Miyake (2004), to increase generalizability also was an important consideration. The disadvantage of this approach is that control of the task demands necessarily is reduced when using commercially available tasks. Therefore, it might be that if these specific demands were varied systematically one at a time, the pattern of results would differ. For example, comparisons between administrations of computerized Shape School tasks with a manual button press versus the verbal naming response would permit further examination of the effect of response type, at least in a task-specific manner. However, this approach is not without its own disadvantages, as the common variance is magnified due to shared methodology, making it difficult to discern the relative differences due to differential task demands (Friedman \& Miyake, 2004).

In summary, these findings support the unique role of short-term memory processes in attentional control tasks in preschool children. Generally, there was communality in inhibitory task demands across instruments, where relevant performance distinctions among children of varying shortterm memory spans were noted on tasks that required attention control, in contrast to those that had greater demands for response suppression. It would be useful to determine whether such a distinction is supported fur- 
ther by inhibitory task performance differences in children with specific neurological, medical, psychiatric, and developmental disorders. Although there are many different approaches to measuring executive control in this age range, there remains comparatively few that combine careful task demand analysis with a consideration of psychometric properties and generalizability. Certainly, there is more work to be done in the efforts to translate basic cognitive neuroscience into use in the clinical context.

\section{Acknowledgments}

This research was supported, in part, by Grant 1R01 MH065668 from the National Institute of Mental Health; Grant 1R01 DA014661 from the National Institute on Drug Abuse; Grant 6R01 HD038051 from the National Institute of Child Health \& Development; the Pediatric Neuropsychology/Developmental Cognitive Neuroscience Award from the Rita Rudel Foundation; the Special Research Program Award from the Southern Illinois University Office of Research Development and Administration to Kimberly Andrews Espy; and grants from the Carnegie Trust and British Academy to Rebecca Bull.

We thank the participating families, undergraduates, medical students, project staff, and graduate students who assisted in various laboratory tasks associated with this study. We also thank Stephanie Carlson for her insightful comments on a previous draft of this article.

\section{References}

Allport, A., Styles, E. A., \& Hsieh, S. (1994). Shifting intentional set: Exploring the dynamic control of tasks. In C. Umilta \& M. Moscovitch (Eds.), Attention and performance XV (pp. 421-452). Cambridge, MA: MIT Press.

Allport, A., \& Wylie, G. (2000). Task switching: Positive and negative priming of task set. In G. W. Humphreys, J. Duncan, \& A. Triesman (Eds.), Attention, space, and action: Studies in cognitive neuroscience (pp. 273-296). London: Oxford University Press.

Anderson, V. (1998). Assessing executive functions in children: Biological, psychological, and developmental considerations. Neuropsychological Rehabilitation, 8 , 319-349.

Anderson, V., Anderson, P., Grimwood, K., \& Nolan, T. (2004). Cognitive and executive functions 12 years after childhood bacterial meningitis: Effect of acute neurologic complications and age of onset. Journal of Pediatric Psychology, 29, 67-82.

Baddeley, A. (1996). Exploring the central executive. Quarterly Journal of Experimental Psychology, 49A, 5-28.

Baddeley, A. D., \& Hitch, G. J. (1994). Developments in the concept of working memory. Neuropsychology, 8, 485-493.

Bedard, A., Ickowicz, A., Logan, G., Hogg-Johnson, S., Schachar, R., \& Tannock, R. (2003). Selective inhibition in children with attention-deficit hyperactivity disorder off and on stimulant medication. Journal of Abnormal Child Psychology, 31, 315-327.

Bishop, D. V. M., Aamodt-Leaper, G., Creswell, C., McGurk, R., \& Skuse, D. H. (2001). Individual differences in cognitive planning on the Tower of Hanoi task: Neuro- 
psychological maturity or measurement error? Journal of Child Psychology and Psychiatry, 42, 551-556.

Bleckley, M. K., Durso, F., Crutchfield, J., Engle, R., \& Khanna, M. (2003). Individual differences in working memory capacity predict visual attention allocation. Psychonomic Bulletin \& Review, 10, 884-889.

Brooks, P. J., Hanauer, J. B., Padowska, B., \& Rosman, H. (2003). The role of selective attention in preschoolers' rule use in a novel dimensional card sort. Cognitive Development, 18, 195-215. Bull, R., \& Brown, E. L. (2004). Understanding the inhibitory processes of the Day-Night task. Manuscript submitted for publication.

Bull, R., Johnston, R. S., \& Roy, J. A. (1999). Exploring the roles of the visual-spatial sketch pad and central executive in children's arithmetical skills: Views from cognition and developmental neuropsychology. Developmental Neuropsychology, $15,421-442$.

Bull, R., \& Scerif, G. (2001). Executive functioning as a predictor of children's mathematics ability: Inhibition, switching, and working memory. Developmental Neuropsychology, 19, 273-293.

Carlson, S. M. (2005/this issue). Developmentally sensitive measures of executive function in preschool children. Developmental Neuropsychology, 28, 595-616.

Carlson, S. M., \& Moses, L. J. (2001). Individual differences in inhibitory control and children's theory of the mind. Child Development, 72, 1032-1053.

Carlson, S. M., Moses, L. J., \& Breton, C. (2002). How specific is the relation between executive function and theory of mind? Contributions of inhibitory control and working memory. Infant \& Child Development, 11, 73-92.

Casey, B. J., Thomas, K. M., Welsh, T. F., Badgaiyan, R., Eccard, C. H., Jennings, J., et al. (2000). Dissociation of response conflict, attentional control, and expectancy with functional magnetic resonance imaging (fMRI). Proceedings of the National Academy of Sciences, USA, 97, 8728-8733.

Cowan, N. (1995). Attention and memory: An integrated framework (Oxford Psychology Series, No. 26). Oxford, UK: Oxford University Press.

Cowan, N. (1999). The differential maturation of two processing rates related to digit span. Journal of Experimental Child Psychology, 72, 193-209.

Dempster, F. N. (1993). Resistance to interference: Developmental changes in a basic processing dimension. In M. L. Howe \& R. Pasnak (Eds.), Emerging themes in cognitive development. Volume I: Foundations (pp. 3-27). New York: Springer-Verlag.

Desimone, R., \& Duncan, J. (1995). Neural mechanisms of selective attention visual attention. Annual Review of Neuroscience, 18, 193-222.

Diamond, A. (1988). Abilities and neural mechanisms underlying AB performance. Child Development, 59, 523-527.

Diamond, A., Briand, L., Fossella, J., \& Gehlbach, L. (2004). Genetic and neurochemical modulation of prefrontal cognitive functions in children. American Journal of Psychiatry, 161, 125-132.

Diamond, A., \& Kirkham, N. (2005). Not quite as grown-up as we like to think: Parallels between cognition in childhood and adulthood. Psychological Science, 16, 291-297.

Diamond, A., Kirkham, N., \& Amso, D. (2002). Conditions under which young children can hold two rules in mind and inhibit a pre-potent response. Developmental Psychology, 38, 352-362. 
Diamond, A., Prevor, M. B., Callender, G., \& Druin, D. P. (1997). Prefrontal cortex cognitive deficits in children treated early and continuously for PKU. Monographs of the Society for Research in Child Development, 62(4), 1-205.

Diamond, A., \& Taylor, C. (1996). Development of an aspect of executive control: Development of the abilities to remember what I said and to "Do as I say, not as I do". Developmental Psychobiology, 29, 315-334.

Durston, S., Thomas, K., Yang, Y., Ulug, A., Zimmerman, R. \& Casey, B. J. (2002). A neural basis for the development of inhibitory control. Developmental Science, 5, F9-F16.

Engle, R. W. (2002). Working memory capacity as executive attention. Current Directions in Psychological Science, 11, 19-23.

Espy, K. A. (1997). The Shape School: Assessing executive function in preschool children. Developmental Neuropsychology, 13, 495-499.

Espy, K. A., Bull, R. B., \& Martin, J. (2005). Measuring the development of executive control with the Shape School. Manuscript submitted for publication.

Espy, K. A., Kaufmann, P. M., \& Glisky, M. L. (1999). Neuropsychological function in toddlers exposed to cocaine in utero: A preliminary study. Developmental Neuropsychology, 15, 447-460.

Espy, K. A., Kaufmann, P. M., Glisky, M. L., \& McDiarmid, M. D. (2001). New procedures to assess executive functions in preschool children. Clinical Neuropsychologist, 15, 46-58.

Espy, K. A., Kaufmann, P. M., McDiarmid, M. D., \& Glisky, M. L. (1999). Executive functioning in preschool children: Performance on A-not-B and other delayed response format tasks. Brain and Cognition, 41, 178-199.

Espy, K. A., McDiarmid, M. D., Cwik, M. F., Senn, T. E., Hamby, A., \& Stalets, M. M. (2004). The contributions of executive functions to emergent mathematic skills in preschool children. Developmental Neuropsychology, 26, 465-486.

Espy, K. A., Stalets, M. M., McDiarmid, M. D., Senn, T. E., Cwik, M. F., \& Hamby, A. (2002). Executive functions in preschool children born preterm: Application of cognitive neuroscience paradigms. Child Neuropsychology, 8, 83-92.

Ewing-Cobbs, L., Prasad, M. R., Landry, S. H., Kramer, L., \& DeLeon, R. (2004). Executive functions following traumatic brain injury in young children: A preliminary analysis. Developmental Neuropsychology, 26, 487-512.

Freidman, N. P., \& Miyake, A. (2004). The relations among inhibition and interference control functions: A latent-variable analysis. Journal of Experimental Psychology: General, 133, 101-135.

Gathercole, S. E., \& Pickering, S. J. (2000). Working memory deficits in children with low achievements in the national curriculum at 7 years of age. British Journal of Educational Psychology, 70, 177-194.

Gerardi-Caulton, G. (2000). Sensitivity to spatial conflict and the development of selfregulation in children 24-36 months of age. Developmental Science, 3, 397-404.

Gerstadt, C. L., Hong, Y. J., \& Diamond A. (1994). The relationship between cognition and action: Performance of 3.5- to 7-year-olds on Stroop-like Day-Night test. Cognition, 53, 129-153.

Han, S-H., \& Kim, M-S. (2004). Visual search does not remain efficient when executive working memory is not working. Psychological Science, 15, 623-628.

Harnishfeger, K. K. (1995). The development of cognitive inhibition: Theories, definitions, and research evidence. In F. N. Dempster \& C. J. Brainerd (Eds.), Interference and inhibition in cognition (pp. 175-204). San Diego, CA: Academic. 
Hughes, C. (1998a). Executive function in preschoolers: Links with theory of mind and verbal ability. British Journal of Developmental Psychology, 16, 233-253.

Hughes, C. (1998b). Finding your marbles: Does preschoolers' strategic behavior predict later understanding of mind. Developmental Psychology, 34, 1326-1339.

Hughes, C., White, A., Sharpen, J., \& Dunn, J. (2000). “Hard-to-manage” preschoolers' peer problems and possible cognitive influences. Journal of Child Psychology \& Psychiatry, 41, 169-179.

Huttenlocher, P. R., \& Dabholkar, A. S. (1997). Developmental anatomy of prefrontal cortex. In N. A. Krasnegor, G. R. Lyon, \& P. S. Goldman-Rakic (Eds.), Development of the prefrontal cortex: Evolution, neurobiology, and behavior (pp. 69-83). Baltimore: Brookes.

Isquith, P. K., Gioia, G. A., \& Espy, K. A. (2004). Executive function in preschool children: Examination through everyday behavior. Developmental Neuropsychology, $26,403-422$.

Kane, M. J., Bleckley, M. K., Conway, A. R. A., \& Engle, R. W. (2001). A controlled-attention view of working-memory capacity. Journal of Experimental Psychology: General, 130, 169-183.

Kane, M. J., \& Engle, R. W. (2000). Working-memory capacity, proactive intereference, and divided attention: Limits on long-term memory retrieval. Journal of Experimental Psychology; Learning, Memory, \& Cognition, 26, 336-358.

Kane, M. J., \& Engle, R. W. (2002). The role of the prefrontal cortex in working memory capacity, executive attention, and general fluid intelligence: An individual differences perspective. Psychonomic Bulletin \& Review, 9, 637-671.

Kane, M. J., \& Engle, R. W. (2003). Working-memory capacity and the control of attention: The contributions of goal neglect, response competition, and task set to Stroop interference. Journal of Experimental Psychology: General, 132, 47-70.

Kinney, H. C., Brody, B. A., Kloman, A. S., \& Gilles, F. H. (1988). Sequence of central nervous system myelination in human infancy. Journal of Neuropathology and Experimental Neurology, 47, 217-234.

Kirkham, N. Z., Cruess, L., \& Diamond, A. (2003). Helping children apply their knowledge to their behavior on a dimension-switching task. Developmental Science, 6, 449-467.

Kochanska, G., Murray, K., Jacques, T., Koenig, A., \& Vandegeest, K. (1996). Inhibitory control in young children and its role in emerging internalization. Child Development, 67, 490-507.

Korkman, M., Kirk, U., \& Kemp, S. (1998). NEPSY: A developmental neuropsychological assessment manual. San Antonio, TX: The Psychological Corporation.

Mayr, U., \& Keele, S. W. (2000). Changing internal constraints on action: The role of backward inhibition. Journal of Experimental Psychology: General, 129, 4-26.

Miller, E. K. (2000). The prefrontal cortex and cognitive control. Nature Neuroscience, $1,59-65$.

Nigg, J. T. (2000). On inhibition/disinhibition in developmental psychopathology: View from cognitive and personality psychology and a working inhibition taxonomy. Psychological Bulletin, 126, 220-246.

Nigg, J. T. (2001). Is ADHD a disinhibitory disorder? Psychological Bulletin, 127, 571-598.

O'Reilly, R. C., Noelle, D. C., Braver, T. S., \& Cohen, J. D. (2002). Prefrontal cortex and dynamic categorization tasks: Representational organization and neuromodulatory control. Cerebral Cortex, 12, 246-257. 
Pennington, B. F., \& Ozonoff, S. (1996). Executive functions and developmental psychopathology. Journal of Child Psychology \& Psychiatry \& Allied Disciplines, 37, 51-87.

Perner, J., \& Lang, B. (2002). What causes 3-year-olds difficulty on the Dimensional Change Card Sorting task? Infant and Child Development, 11, 93-105.

Perner, J., Lang, B., \& Kloo, D. (2002). Theory of mind and self control: More than a common problem of inhibition. Child Development, 73, 752-767.

Posner, M. I., \& Petersen, S. E. (1990). The attention system of the human brain. Annual Review of Neuroscience, 13, 25-42.

Prevor, M., \& Diamond, A. (2005). Color-object interference in young children: A Stroop effect in children 31/2 to 61/2 years old. Cognitive Development, 20, 256-278.

Ready, R., Stierman, L., \& Paulsen, J. S. (2001). Ecological validity of neuropsychological and personality measures of executive functions. The Clinical Neuropsychologist, 15, 314-323.

Reed, M. A., Pien, D. L., \& Rothbart, M. K. (1984). Inhibitory self-control in pre-school children. Merrill-Palmer Quarterly, 30, 131-147.

Rennie, D., Bull, R., \& Diamond, A. (2004). Executive functioning in preschoolers: Reducing the inhibitory demands of the Dimensional Change Card Sort task. Developmental Neuropsychology, 26, 423-443.

Roberts, R. J., Jr., \& Pennington, B. F. (1996). An interactive framework for examining prefrontal cognitive processes. Developmental Neuropsychology, 12, 105-126.

Shilling, V. M., Chetwynd, A., \& Rabbitt, P. M. A. (2002). Individual inconsistency across measures of inhibition: An investigation of the construct validity of inhibition in older adults. Neuropsychologia, 40, 605-619.

Thatcher, R. W. (1997). Human frontal lobe development: A theory of cyclical cortical reorganization. In N. A. Krasnegor, G. R. Lyon, \& P. S. Goldman-Rakic (Eds.), Development of the prefrontal cortex: Evolution, neurobiology, and behavior (pp. 85-113). Baltimore: Brookes.

Tipper, S. P., \& Cranston, M. (1985). Selective attention and priming: Inhibitory and facilitatory effects of ignored primes. Quarterly Journal of Experimental Psychology, 37, 591-611.

Welsh, M. C., Pennington, B. F., \& Groisser, D. B. (1991). A normative-developmental study of executive function: a window on prefrontal function in children. Developmental Neuropsychology, 7, 131-149.

Wilson, S. P., \& Kipp, K. (1998). The development of efficient inhibition: Evidence from directed-forgetting tasks. Developmental Review, 18, 86-123.

Wright, I., Waterman, M., Prescott, H., \& Murdoch-Eaton, D. (2003). A new stroop-like measure of inhibitory function development: Typical developmental trends. Journal of Child Psychology \& Psychiatry, 44, 561-575.

Zelazo, P. D., Frye, D., \& Rapus, T. (1996). An age-related dissociation between knowing rules and using them. Cognitive Development, 11, 37-63.

Zelazo, P. D., Müller, U., Frye, D., \& Marcovitch, S. (2003). The development of executive function in childhood. Monographs of the Society for Research in Child Development, 68 (3, Serial No. 274). 